Order of mixture. Methyl cellulose and vaseline should be mixed together with an electric mixer. Then add the calcium carbonate while mixing and finally add the mineral oil. Combine the "Diet-Pepsi" and water and mix slowly into the solid mixture.

Nutritive Substance. (approximately $4.00 \mathrm{cal} / \mathrm{g}$ ) $50 \mathrm{~g}$ methyl cellulose (4000 centipoise, Fisher Scientific)

43 g "Crisco"

$20 \mathrm{~g}$ vitamin free casein (Nutritional Biochemicals)

$33 \mathrm{~g}$ sugar (confectioners grade)

$4 \mathrm{~g}$ salt mixture (U.S.P. XIV, Nutritional Biochemicals)

$45 \mathrm{ml}$ "Pepsi-Cola" (non-carbonated fountain syrup)

$55 \mathrm{ml}$ tap water

Order of mixture. Add all of the dry ingredients together and mix with an electric mixer. Combine the "Pepsi-Cola" and water and mix slowly into the solid mixture.

For larger amounts of substance, it is advised that smaller mixtures of the proportions indicated be made and combined, since doubling and tripling the amounts indicated often causes variation in the mixtures. Also, because of the nature of the methyl cellulose and the way in which it combines with other ingredients, the above amounts are only approximate. At times it is necessary to add an additional, small amount of one of the ingredients to a substance so as to equalize its texture to that of the other substance. The above formulas are accurate within $5 \%$; therefore, ingredients should not be added above that percentage amount. The order of mixture is important. Adding the liquids last prevents gumming of the methyl cellulose and provides the resultant smooth texture.

These two substances provide a means of varying natural ingestion of bulk. Such a methodology allows: (a) variation of body weight on an ad lib feeding schedule, (b) study of the consummatory response as it is influenced by bulk aspects of the diet, and (c) variation of quality of a reinforcer on a caloric basis. The natural ingestion aspect of these materials provides a procedural advantage over the surgical and stimulus-confounding problems in previous bulk experiments.

REFERENCES

BOLLES, R. C. Readiness to eat: effects of age, sex, and weight loss. $J$. comp. physiol Psychol., 1965, 60, 88-92.

CORBIT, J. D., \& STELLAR, E. Palatability, food intake, and obesity in normal and hyperphagic rats. J. comp. physiol. Psychol. 1964, 58, 63-67.

SMITH, M., POOL, R., \& WEINBERG, H. The role of bulk in the control of eating. J. comp. physiol Psychol, 1962, 55, 115-120.

TAYLOR, C. J.. \& BRUNING, J. L. Effects of nonnutritive bulk on eating behavior. J. comp. physiol. Psychol., 1967, 64, 353-355.

\title{
A note on luminance control in tachistoscopes
}

\author{
MICHAEL H. SIEGEL, RIPON COLLEGE, Ripon, Wisconsin \\ 54971
}

Procedures are described for measuring tachistoscopic luminance levels for brief light flashes and over longer intervals. Stability of luminance levels is discussed for both conditions.

In several articles concerned with reporting perceptual research in which tachistoscopes were used, the luminance level has been critical. In many reports, the investigator has obviously gone to a great deal of trouble to specify the luminance conditions at the start of experimentation. Implicit in statements reporting a given luminance level is the assumption that the luminance remains constant. Unfortunately, with phosphor-coated light sources, this assumption is not correct.

I have conducted a reasonably thorough calibration of two different commercial, three channel tachistoscopes powered by the standard phosphor-coated light sources. Over a series of several days the following procedure was used. A Spectra Brightness Spot Meter calibrated to read directly in $\mathrm{ft}-\mathrm{L}$ was focused upon a 5 by 7 in. white card placed in one channel of the tachistoscope. The lamp was allowed to burn continuously. Potentiometers on the instrument used to control luminance were set to one of three positions. The same white card was used in each channel. Eventually, data were obtained for nine separate conditions, the three channels each at three different potentiometer settings. Luminance readings were made when the lamp was first turned on and at each succceding minute for at least 10 min. In every case luminance increased as a function of the amount of time the lamp had been burned. In every case the luminance level reached a point of stability, but in some cases this required 15 min of continuous operation of the lamp.
Measurements were also made of the luminance of brief light flashes. Because of the lag of the photometer, it was necessary to employ a different method of measuring luminance. A photo cell $^{t}$ and oscilloscope proved adequate. When the same caibration procedure was used as with the continuously burning lamp, essentially the same results were found. In each case initial measurements of luminance were low and later measurements were higher. Furthermore, on days in which the room temperature was low, initial luminance readings were particularly low. In addition, when very brief flashes, up to $20 \mathrm{msec}$, were used with relatively long off periods, about $1 \mathrm{sec}$, the luminance never stabilized. Apparently, in order to reach a point of stability. lamps must achieve a certain temperature. When operated continuously, such temperature is reached, usually within 7 or 8 min. With brief flashes, some of the heat generated can dissipate while the lamp is off and stability may never be achieved.

Luminance is clearly a function of temperature. The tachistoscope with the photometer is, in effect, a reliable though expensive thermometer. When the tachistoscope is used in the manner in which it was designed to be used, namely, as an instrument to deliver very brief light flashes, it is unexcelled. When, instead, it is used where the luminance requirement i: critical or where the spectral composition of the light must remain invariant, the apparatus will be found wanting. If luminance control is more important to the experimenter than the very brief exposure permitted by the phosphor-coated lamps. a mechanical shuttering system together with a light source which remains on constantly is advisable.

\section{NOTE}

1. The 934 photo tube is a vacuum type with fast response. It peaks at $4000 \mathrm{~A}$. 